\title{
Hydrogen sulfide attenuates cardiac hypertrophy and fibrosis induced by abdominal aortic coarctation in rats
}

\author{
JINGLONG HUANG ${ }^{*}$, DONGMING WANG ${ }^{*}$, JINBIN ZHENG, XIANSHENG HUANG and HONG JIN \\ Department of Cardiology, Medical College, The First Affiliated Hospital of \\ Shantou University, Shantou, Guangdong 515041, P.R. China
}

Received October 26, 2011; Accepted December 27, 2011

DOI: $10.3892 / \mathrm{mmr} .2012 .748$

\begin{abstract}
Hydrogen sulfide $\left(\mathrm{H}_{2} \mathrm{~S}\right)$ has been recently found to be an endogenous signaling gasotransmitter. Cardiac hypertrophy often develops in the course of heart failure. It is unknown whether or not endogenous $\mathrm{H}_{2} \mathrm{~S}$ protects cardiac hypertrophy. This study was conducted to examine the effects of $\mathrm{H}_{2} \mathrm{~S}$ on cardiac hypertrophy and fibrosis induced by abdominal aortic coarctation and to explore its mechanisms. Male SpragueDawley rats were randomly divided into five groups: normal, sham, abdominal aortic coarctation (AAC), AAC treated with enalapril and AAC treated with $\mathrm{H}_{2} \mathrm{~S}$. One week after surgery, enalapril and sodium hydrosulfide (NaHS)-treated rats were fed for 28 consecutive days and sacrificed. After that, the left ventricle mass index (LVMI), cardiomyocyte size and areas, collagen volume fraction (CVF) of the rats were measured. In the AAC rats, the LVMI, the cardiomyocyte size and areas, and the CVF were all markedly increased while in the $\mathrm{H}_{2} \mathrm{~S}$ groups they were significantly reduced. $\mathrm{H}_{2} \mathrm{~S}$ decreased the levels of Ang-II in the heart, but not in plasma. In addition, $\mathrm{H}_{2} \mathrm{~S}$ also improved the expression of connexin 43 (Cx43). Our results suggest that $\mathrm{H}_{2} \mathrm{~S}$ can significantly suppress cardiac hypertrophy and fibrosis induced by overloaded pressure, possibly by inhibiting the activity of intracardiac Ang-II and by modifying expression of $\mathrm{Cx} 43$.
\end{abstract}

\section{Introduction}

Cardiac hypertrophy, usually considered as an effective compensation mechanism, can maintain or even increase cardiac output. However, in the long term, persistent hypertrophy can ultimately progress to cardiac dilatation, decreased ejection fraction finally leading to heart failure (1). Pathological

Correspondence to: Dr Hong Jin, Department of Cardiology, Medical College of The First Affiliated Hospital of Shantou University, Shantou, Guangdong 515041, P.R. China

E-mail: j.cherry@yahoo.cn

*Contributed equally

Key words: hydrogen sulfide, cardiac hypertrophy, angiotensin II changes in ventricular hypertrophy often manifest while the morphology of cardiomyocytes is altered, such as changes in cardiomyocyte hypertrophy, interstitial fibrosis $(2,3)$ and gene expression (4). Clinically, cardiac hypertrophy caused by various reasons involves different levels of cardiac matrix changes, especially in hypertensive heart disease $(5,6)$. It has been reported in both animal and human studies that in left ventricular hypertrophy (LVH), gene expression alterations in connexin 43 (Cx43), as well as gap junction disorganization, are the basis for the triggering and maintainence of arrhythmias (7-9). Therefore, the regression of cardiac hypertrophy is associated with a decreased risk of cardiovascular diseases.

Hydrogen sulfide $\left(\mathrm{H}_{2} \mathrm{~S}\right)$ is well known as a noxious gas in living organisms (10). However, it is increasingly recognized that like nitric oxide and carbon monoxide, $\mathrm{H}_{2} \mathrm{~S}$ is a member of the family of 'gaseous transmitters'. Studies have indicated that, although in low amounts, $\mathrm{H}_{2} \mathrm{~S}$ can be produced in mammalian tissues, and is controlled by several pyridoxal-5'-phosphate (PLP)-dependent enzymes, including cystathionine $\beta$-synthase (CBS), cystathionine $\gamma$-lyase (CSE) $(10,11)$, and a newly identified enzyme, 3-mercaptopyruvate sulfurtransferase (3-MST) $(12,13)$. Moreover, increasing evidence has shown that $\mathrm{H}_{2} \mathrm{~S}$ plays important roles in various systems, particularly in the cardiovascular system (14), regulating vascular tone (15) and protecting heart from ischemic injury (16). These various actions highlight the potential important functions of $\mathrm{H}_{2} \mathrm{~S}$ for modulation of the cardiovascular system. While cardiac hypertrophy is a major risk factor for the development of several cardiovascular diseases, it is still unknown whether endogenous $\mathrm{H}_{2} \mathrm{~S}$ restrains cardiac hypertrophy.

In the present study, an in vivo model of abdominal aortic coarctation was used. This is the most commonly used method in cardiac hypertrophy research (17). During this study, we investigated the effects of $\mathrm{H}_{2} \mathrm{~S}$ administration on cardiac hypertrophy and fibrosis, levels of Ang-II in cardiac tissues and plasma, as well as the expression levels of $\mathrm{Cx} 43$.

\section{Materials and methods}

Materials. The animal experiments complied with the guidance for the Care and Use of Laboratory Animals of Shantou University Medical College. Adult male Sprague-Dawley rats (170-190 g) were provided by the Animal Department of Shantou University Medical College. 
Table I. LV weight normalized to body weight (LVW/BW) was used as an index of cardiac mass for the determination of cardiac hypertrophy.

\begin{tabular}{lccccc}
\hline & Initial BW $(\mathrm{g})$ & Final BW $(\mathrm{g})$ & Increased BW $(\mathrm{g})$ & LVW $(\mathrm{mg})$ & LVW/BW $(\mathrm{mg} / \mathrm{g})$ \\
\hline normal & $180 \pm 10$ & $276 \pm 31$ & $96 \pm 23$ & $582 \pm 62$ & $2.11 \pm 0.14$ \\
sham & $175 \pm 3$ & $276 \pm 27$ & $101 \pm 26$ & $570 \pm 69$ & $2.06 \pm 0.07$ \\
AAC & $173 \pm 2$ & $294 \pm 25$ & $125 \pm 24$ & $771 \pm 126^{\mathrm{a}, \mathrm{b}}$ & $2.67 \pm 0.23^{\mathrm{a}, \mathrm{b}}$ \\
$\mathrm{AAC}+\mathrm{EN}$ & $179 \pm 9$ & $234 \pm 22$ & $54 \pm 17$ & $590 \pm 67^{\mathrm{a}, \mathrm{b}, \mathrm{c}}$ & $2.50 \pm 0.17^{\mathrm{a}, \mathrm{b}, \mathrm{c}}$ \\
$\mathrm{AAC}+\mathrm{H}_{2} \mathrm{~S}$ & $179 \pm 11$ & $239 \pm 16$ & $57 \pm 15$ & $609 \pm 76^{\mathrm{a}, \mathrm{b}, \mathrm{c}}$ & $2.55 \pm 0.16^{\mathrm{a}, \mathrm{b}, \mathrm{c}}$ \\
\hline
\end{tabular}

Values are indicated as means \pm standard error $(\mathrm{n}=8-11)$. ${ }^{\mathrm{a}} \mathrm{P}<0.05 \mathrm{vs}$. normal; ${ }^{\mathrm{b}} \mathrm{P}<0.05 \mathrm{vs}$. sham; ${ }^{\mathrm{c}}<0.05$ vs. AAC group.

Sodium hydrosulfide (NaHS) was purchased from Sigma (St. Louis, MO, USA). The Ang-II assay ELISA kit for rat was purchased from Uscnlife Sciences Co., Ltd. (Wuhan, China). The rabbit monoclonal antibody against $\mathrm{Cx} 43$ was purchased from Abcam PLC (UK).

Abdominal aortic constriction. Abdominal aortic coarctation was carried out as described by Phrommintikul et al (17) with a few modifications. Rats were anesthetized with sodium pentobarbital $(40 \mathrm{mg} / \mathrm{kg})$. Under sterile conditions, the skin was cut open along the abdominal midline, $4 \mathrm{~cm}$ away from the xiphoid process. The incision was sutured layer after layer and the animals were injected with penicillin prophylaxis. Sham-operated animals serving as controls were subjected to the same surgical procedure except that the aorta was not constricted.

Experimental design. Adult male Sprague-Dawley rats, 8 -weeks old, were divided randomly into 3 groups as shown in Table I: i) untreated control (normal, $n=10$ ); ii) sham-operated group (sham, $\mathrm{n}=10$ ); iii) abdominal aortic coarctation group (AAC, $n=80$ ). One week later, those survival AAC rats were divided randomly again into three groups: i) abdominal aortic coarctation only (AAC, $n=14)$; ii) surgery plus enalapril given by direct gastric gavage (AAC+EN, $5 \mathrm{mg} / \mathrm{kg} / \mathrm{day}, \mathrm{n}=14$ ); iii) surgery plus hydrogen sulfide administered intraperitoneally (i.p.) $\left(\mathrm{AAC}+\mathrm{H}_{2} \mathrm{~S}, 14 \mu \mathrm{mol} / \mathrm{kg} / \mathrm{day}, \mathrm{n}=14\right)$. Five weeks after the surgery, the rats were anesthetized and their hearts were removed for following analyses.

Determination of cardiac hypertrophy index. The rats were weighed and then anesthetized with sodium pentobarbital $(40 \mathrm{mg} / \mathrm{kg}$ i.p.). The rat heart was removed and rinsed thoroughly with cold saline, having washed off the blood. The atria, great vessels, and the right ventricle along its septal insertion were snipped off. Data were expressed as left ventricular weight/body weight ratio $(\mathrm{mg} / \mathrm{g})$ and were used as an index of cardiac hypertrophy.

Measurement of endogenous $\mathrm{H}_{2} \mathrm{~S}$ concentration in plasma. The first $75 \mu 1$ of plasma was infused into a tube, with the addition of $250 \mu 1$ of $1 \%(\mathrm{w} / \mathrm{v})$ zinc acetate and $425 \mu 1$ of distilled water, followed by successive addition of $20 \mu \mathrm{M} \mathrm{N}$-dimethylp-phenylenediamine sulphate in $7.2 \mathrm{mM} \mathrm{HCl}(133 \mu 1)$ and

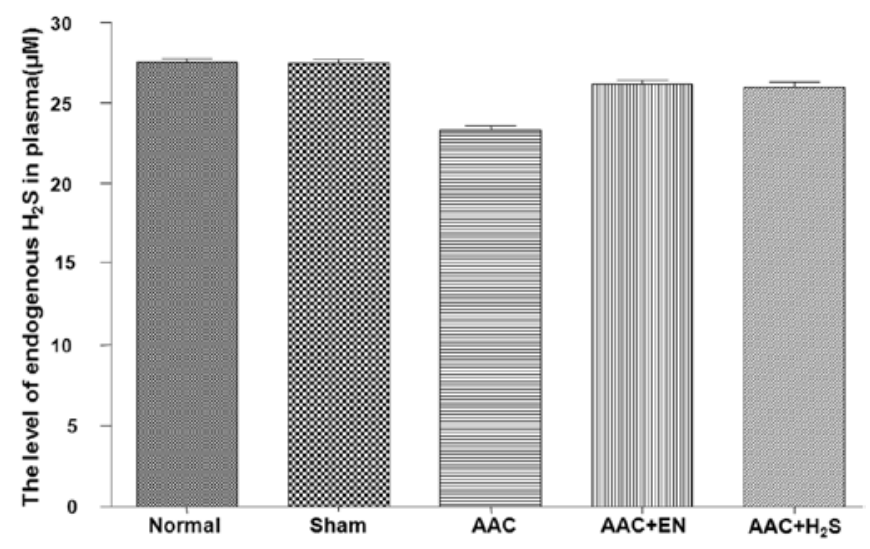

Figure 1. Concentrations of endogenous hydrogen sulfide in plasma. All results are expressed as the mean \pm standard error. AAC vs. normal, $\mathrm{P}<0.05 ; \mathrm{AAC}$ vs. sham, $\mathrm{P}<0.05 ; \mathrm{AAC}+\mathrm{EN}$ vs. $\mathrm{AAC}, \mathrm{P}<0.05 ; \mathrm{AAC}+\mathrm{H}_{2} \mathrm{~S}$ vs. AAC, $\mathrm{P}<0.05$.

$30 \mu \mathrm{M} \mathrm{FeCl}_{3}$ in $1.2 \mathrm{mM} \mathrm{HCl}(133 \mu \mathrm{l})$. The test tubes were kept at room temperature for a 10-min incubation. Then, $250 \mu 1$ of $10 \%$ tricholoacetic acid was added to the reaction mixture, to remove the protein from the plasma. The OD was measured with a spectrophotometer at $670 \mathrm{~nm}$.

Histopathological and immunohistochemical analyses. The ventricles were fixed in $10 \%$ formaldehyde and cut into thin sections $(5 \mu \mathrm{m})$, followed by staining with hematoxylin and eosin and picrosirius red in order to determine the degree of collagen fiber accumulation. The pathological slides were stained with picrosirius red, and 8 fields were randomly selected for observation.

Hearts from each group of rats were prepared for immunohistochemical analysis. A rabbit monoclonal antibody specific to $\mathrm{Cx} 43$ was applied at $4^{\circ} \mathrm{C}$ overnight. After being washed with PBS, the slides were incubated with biotinylated goat antirabbit IgG (Santa Cruz Biotechnology, Inc., Santa Cruz, CA, USA) for $30 \mathrm{~min}$ at room temperature. The immunoreactivity was visualized by the streptavidin peroxidase staining method.

Determination of hydroxyproline (Hyp) concentration incardiac tissue. Hyp was measured by the modified alkaline hydrolysis method of Reddy and Enwemeka (18) with modifications. The absorbance was read at $550 \mathrm{~nm}$ using a spectrophotometer. 
A

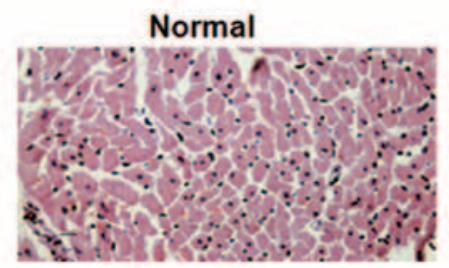

$A A C+E N$

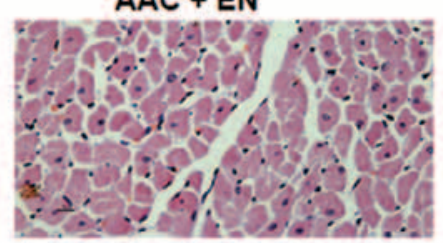

B

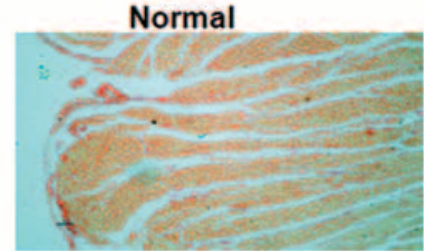

$A A C+E N$

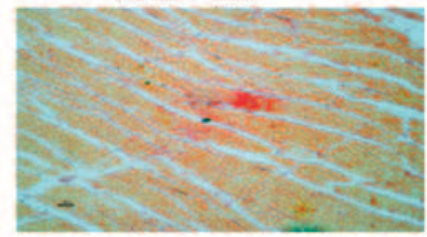

Sham

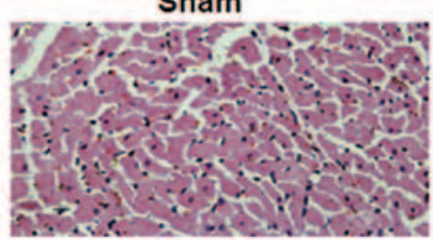

$A A C+\mathrm{H}_{2} \mathrm{~S}$

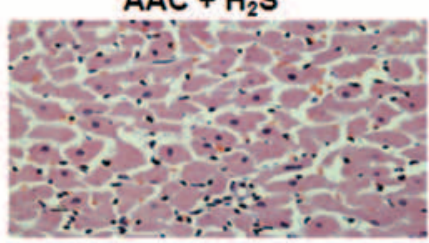

Sham

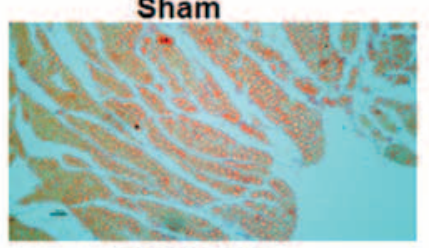

$\mathrm{AAC}+\mathrm{H}_{2} \mathrm{~S}$

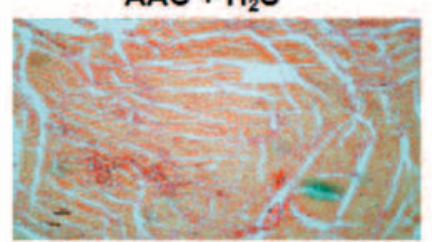

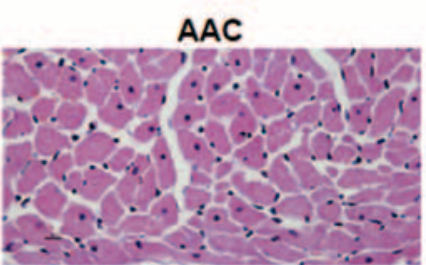
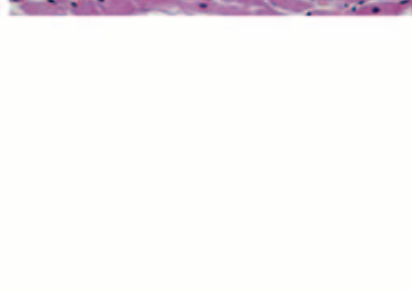

(1)

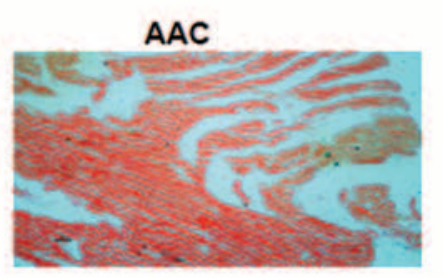

.

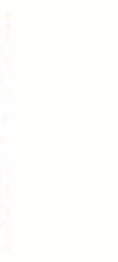

Figure 2. (A) Cross and longitudinal sections of the left ventricle (LV) stained with hematoxylin and eosin. Original magnification (x200). The minimum size of cardiomyocytes was noted. (B) Collagen deposition. Light micrographs of cardiac fibrosis on LV sections. All sections were stained with picrosirius red stain. Magnification, x200.

Total collagen content was calculated from the Hyp concentration assuming that Hyp constitutes $12.5 \%$ collagen.

Angiotensin II in plasma and cardiac concentrations. The concentrations of angiotensin II within the ventricle and plasma were measured with the method of ELISA. Absorbance was recorded at $450 \mathrm{~nm}$, and the concentration was calculated from the generated standard curve of angiotensin II.

Statistical analyses. For comparison among groups, statistical analyses were performed using one-way analysis of variance followed by post hoc Tukey's test (SPSS 13.0, Chicago, IL). All values are expressed as the means \pm SD. Prism 4.0 (GraphPad Software, La Jolla, CA) was used to produce graphs and curve fits. A P-value of $<0.05$ was taken to indicate statistical significance.

\section{Results}

$\mathrm{H}_{2} \mathrm{~S}$ ameliorates left ventricle hypertrophy induced by abdominal aorta coarctation. To determine whether $\mathrm{H}_{2} \mathrm{~S}$ affects the left ventricle hypertrophy induced by aorta coarctation, abdominal aortic constriction (AAC groups) was conducted. Sham-operated animals (sham groups) serving as controls were subjected to the same surgical procedure except that the aorta was not constricted. The untreated animals (normal groups) were also used as controls.
Thirty-five days after the surgery of aortic constriction, the weight of the left ventricle (LVW) normalized to body weight (BW) increased significantly. When compared to the sham group, the ventricular mass index of the model group increased by $29.6 \%$ (Table I), while the weight and quality index of the left ventricle of the group treated with NaHS $(14 \mu \mathrm{mol} / \mathrm{kg} /$ day $)$ was reduced by $21.0 \%(\mathrm{P}<0.05)$ and $4.49 \%$ $(\mathrm{P}<0.05)$, respectively. The left ventricle weight and quality index of the left ventricle of the enalapril-treated $(5 \mathrm{mg} / \mathrm{kg} /$ day) group decreased by $23.4 \%(\mathrm{P}<0.05)$ and $6.38 \%(\mathrm{P}<0.05)$, respectively. Therefore, these results suggest that $\mathrm{H}_{2} \mathrm{~S}$ ameliorates the left ventricle hypertrophy induced by abdominal aorta coarctation.

Endogenous $\mathrm{H}_{2} \mathrm{~S}$ concentrations in plasma. After surgery, the concentration of endogenous $\mathrm{H}_{2} \mathrm{~S}$ significantly declined (Fig. 1). The contents of endogenous $\mathrm{H}_{2} \mathrm{~S}$ of the AAC rats, which were treated with enalapril, significantly increased, while the levels of endogenous $\mathrm{H}_{2} \mathrm{~S}$ in the rats which received NaHS i.p., obviously increased.

$\mathrm{H}_{2} \mathrm{~S}$ improves histological changes in rats treated with abdominal aorta coarctation. Microscopic examination showed that cardiomyocyte hypertrophy, as evidenced by the minimum sizes of cells and cardiomyocyte areas, was significantly increased in AAC rats (Fig. 2A). The cardiomyocyte hypertrophy in enalapril rats was lower than that in the model control, 


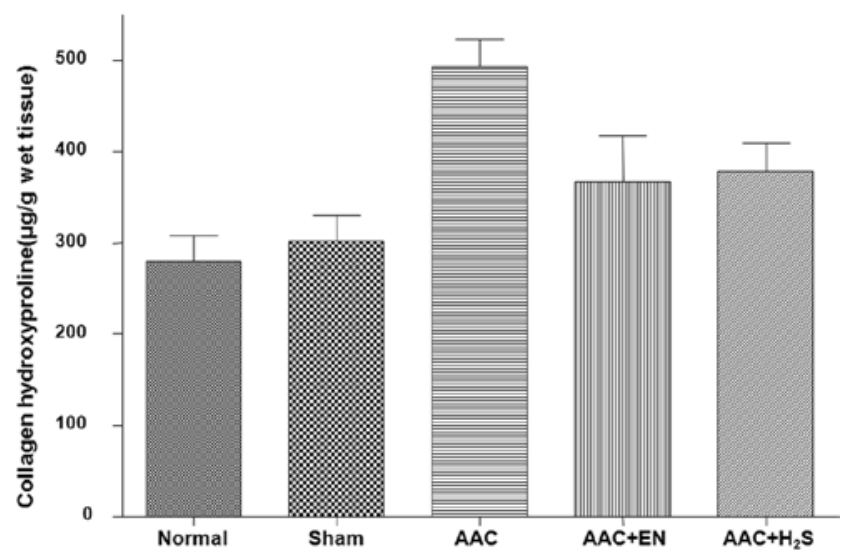

Figure 3. Hydroxyproline concentration in the cardiac tissue was measured with the modified alkaline hydrolysis method. Values are expressed as the means \pm standard error of the measurements. For all statistical comparisons, $\mathrm{n}=8-11$ animals. $\mathrm{P}<0.05, \mathrm{AAC} / \mathrm{AAC}+\mathrm{EN} / \mathrm{AAC}+\mathrm{H}_{2} \mathrm{~S}$ vs. normal; $\mathrm{P}<0.05$ $\mathrm{AAC} / \mathrm{AAC}+\mathrm{EN} / \mathrm{AAC}+\mathrm{H}_{2} \mathrm{~S}$ vs. sham; $\mathrm{P}<0.05, \mathrm{AAC}+\mathrm{EN} / \mathrm{AAC}+\mathrm{H}_{2} \mathrm{~S}$ vs AAC. EN, enalapril.

but was still higher than that in the sham control. Moreover, the administered $\mathrm{H}_{2} \mathrm{~S}$ obviously decreased the minimum sizes of cells and areas, when compared to AAC rats.

$\mathrm{H}_{2} \mathrm{~S}$ significantly suppresses development of cardiac fibrosis. The myocardial fibrosis conditions were measured through Picro-Sirius red staining. The AAC rats showed a significant increase in cardiac fibrosis levels when compared to the sham group (Fig. 2B). For rats in the enalapril or $\mathrm{H}_{2} \mathrm{~S}$ groups, the collagen densities were significantly lower than those in the AAC group, but were still higher than those in the sham group. The Hyp content was significantly increased in the AAC group

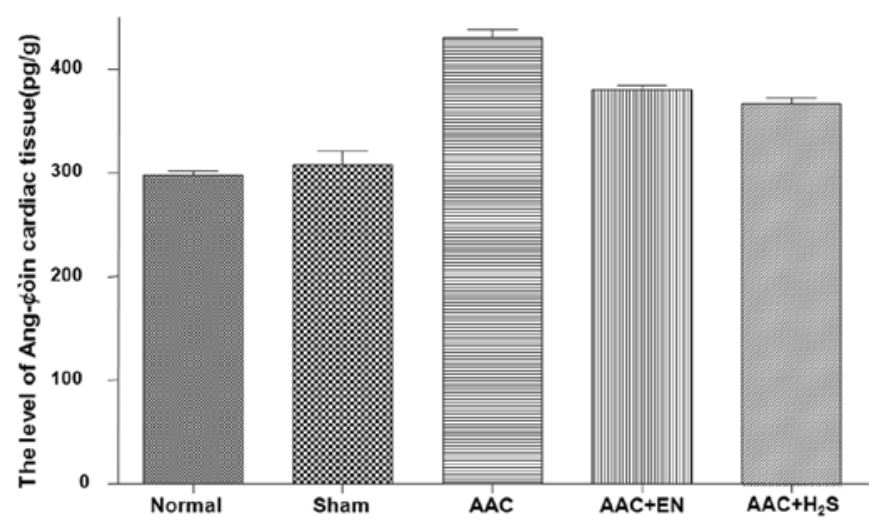

Figure 4. Angiotensin II concentration in cardiac tissues was detected by ELISA. Values are expressed as the mean \pm standard. $\mathrm{P}<0.05, \mathrm{AAC} /$ $\mathrm{AAC}+\mathrm{EN} / \mathrm{AAC}+\mathrm{H}_{2} \mathrm{~S}$ vs. normal; $\mathrm{P}<0.05$, $\mathrm{AAC} / \mathrm{AAC}+\mathrm{EN} / \mathrm{AAC}+\mathrm{H}_{2} \mathrm{~S}$ vs sham; $\mathrm{P}<0.05, \mathrm{AAC}+\mathrm{EN} / \mathrm{AAC}+\mathrm{H}_{2} \mathrm{~S}$ vs. AAC. EN, enalapril.

(Fig. 3). Treatments with enalapril or $\mathrm{H}_{2} \mathrm{~S}$ attenuated increases in the Hyp content.

Angiotensin II content in plasma and cardiac tissues. In the cardiac tissues, the Ang-II concentration markedly increased in the AAC group when compared to the sham control group (Fig. 4). The increase in tissues was blocked by enalapril. $\mathrm{H}_{2} \mathrm{~S}$ could also obviously reduced the high Ang-II contents subjected to AAC. However, in the plasma, the concentrations of Ang-II were not significantly different among the groups (data not shown).

Expression of Cx43 in the myocardial tissues by immunohistochemical analysis. In the AAC group, a significant decrease in

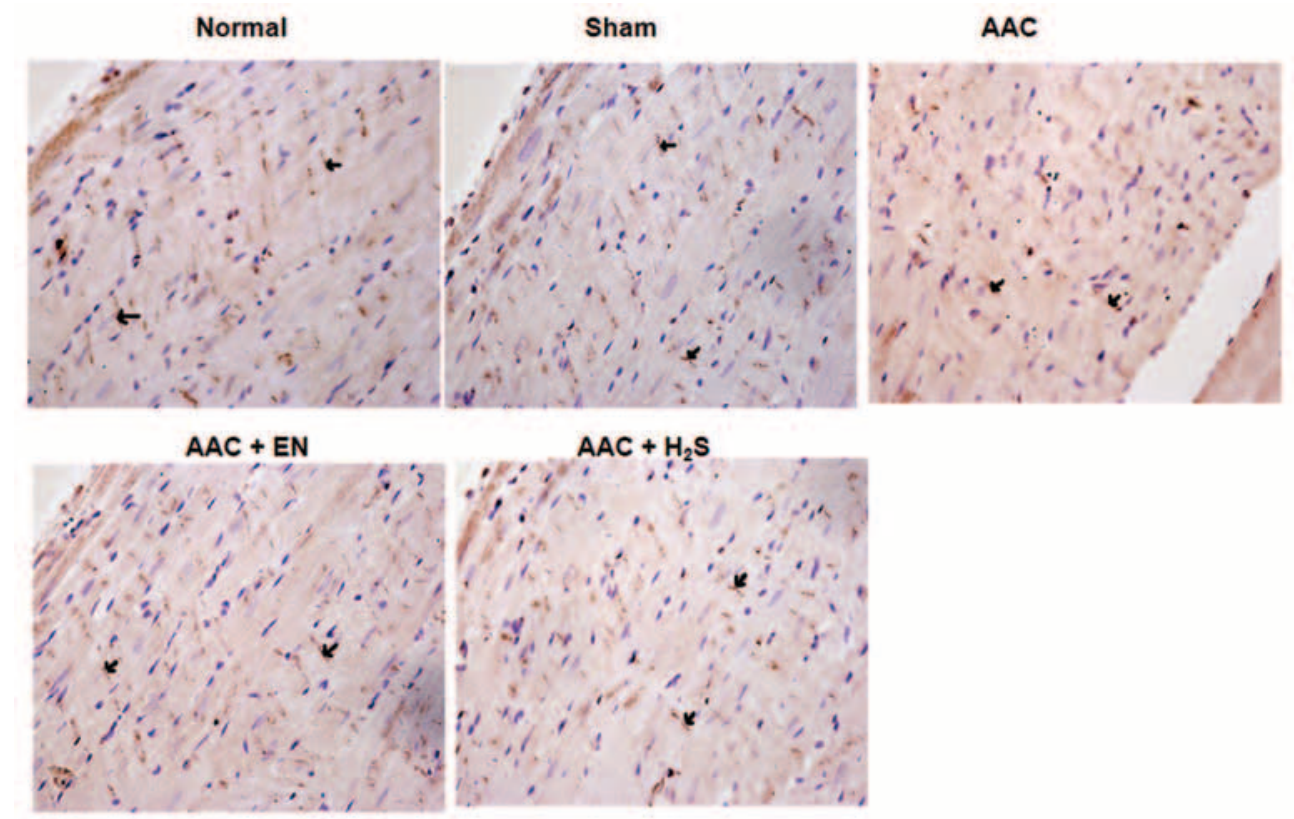

Figure 5. Expression of connexin 43 (Cx43) in myocardial tissues as detected with the method of imunohistochemical analysis. Cx43 is indicated by the black arrows. Sections from the AAC $+\mathrm{EN}$ (abdominal aortic coarctation plus enalapril, $5 \mathrm{mg} / \mathrm{kg} / \mathrm{day}$ ), and AAC $+\mathrm{H}_{2} \mathrm{~S}$ (abdominal aortic coarctation plus hydrogen sulfide, $14 \mu \mathrm{mol} / \mathrm{kg} /$ day) groups are shown. Original magnification, $\mathrm{x} 200$. 
the density of $\mathrm{Cx} 43$ was observed, when compared to the sham group (Fig. 5). However, enalapril administration ameliorated expression of $\mathrm{Cx} 43$, which was also noted in the $\mathrm{H}_{2} \mathrm{~S}$ group.

\section{Discussion}

This study successfully designed a model of myocardial hypertrophy through the partial ligation of abdominal aorta of rats. The presence of myocardial hypertrophy was proven with typical pathological changes, such as left ventricle hypertrophy (LVH) (17) and significant thickness of the left ventricle wall and cardiomyocyte hypertrophy (19). The study results showed that the myocardial tissue had increased fibrosis and collagen deposition in the AAC rats. We also found that the Ang-II expression was upregulated accompanied by cardiac hypertrophy in the model group and this is consistent with previous reports $(20,21)$.

We discovered that compared with those of the sham group, the levels of endogenous $\mathrm{H}_{2} \mathrm{~S}$, a newly recognized gas transmitter $(10,11)$, were greatly decreased in AAC-induced LVH rats, suggesting that the endogenous $\mathrm{H}_{2} \mathrm{~S}$ system may be impaired in the process of cardiac hypertrophy induced by pressure-overload. In addition, the $\mathrm{H}_{2} \mathrm{~S}$ level was notably elevated in rats administered enalapril, yet the relevant mechanism is still not clear. The results also revealed that exogenous administration of $\mathrm{H}_{2} \mathrm{~S}$ via $\mathrm{NaHS}$ significantly suppressed the development of cardiac hypertrophy induced by pressureoverload, and also greatly downregulated the Ang-II levels in cardiac tissue. These results suggest that $\mathrm{H}_{2} \mathrm{~S}$ plays a pivotal role in the development of pressure overload-induced cardiac hypertrophy. The mechanism may be that $\mathrm{H}_{2} \mathrm{~S}$, containing a sulfhydryl-group, interacts with the zinc ion in the active center of the angiotensin-converting enzyme (ACE) to modulate enzyme activity (22) suppressing the Ang-II-induced cardiac hypertrophy. This is supported by the research of Laggner et al (23), who found that $\mathrm{H}_{2} \mathrm{~S}$ exerted protection in the vasculature by reducing the production of Ang-II and inhibiting bradykinin degradation. However, this experiment found no difference in the expression of Ang-II in plasma among the groups, proving that Ang-II in circulation has no correlation with the development of cardiac hypertrophy. Moreover, $\mathrm{H}_{2} \mathrm{~S}$ has also been described as an effective antioxidant which increases glutathione production and suppresses oxidative stress and oxygen species production. Oxygen species are often increased during cardiac hypertrophy in response to various stressors $(24,25)$. Therefore, although the effects of $\mathrm{H}_{2} \mathrm{~S}$ on oxidative stress could not be clarified in the present study, we could not exclude the possibility that direct or indirect suppression of oxidative stress might be the relevant mechanism of $\mathrm{H}_{2} \mathrm{~S}$ to suppress the development of cardiac hypertrophy.

Myocardial fibrosis is often associated with cardiac hypertrophy, with the increase in extracellular matrix, such as collagen $(5,6)$. Progressive myocardial fibrosis contributes necessarily to an increase in cardiac muscle stiffness, ultimately leading to impairment of cardiac function. The results of this study showed that the rats treated with AAC had obvious cardiac fibrosis, while treatment with enalapril obvious suppressed the development of myocardial fibrosis, and this is consistent with a previous report (26). Our results revealed for the first time that $\mathrm{H}_{2} \mathrm{~S}$ also markedly prevents the development of cardiac fibrosis, decreasing the collagen content in the cardiac tissue, yet the detailed signaling pathway mechanism was not yet elucidated. Li et al (27) reported that $\mathrm{H}_{2} \mathrm{~S}$ may reduce collagen accumulation in the pulmonary artery through increasing its degradation by regulating matrix metalloproteinase (MMPs) and metalloproteinase (TIMPs) activities. This needs to be confirmed in future studies on hypertrophied ventricle.

Our study also showed that $\mathrm{H}_{2} \mathrm{~S}$ ameliorated the expression of $\mathrm{Cx} 43$ in cardiac tissue. $\mathrm{Cx} 43$ is the principal connexin in the mammalian ventricle and has been proven to have a close association with cardiac hypotrophy or arrhythmia (28). Roell et al (28) pointed out that engraftment of Cx43-expressing myocytes has the potential of reducing life-threatening postinfarct arrhythmias through the augmentation of intercellular electrical conduction. We also found that the expression of Cx43 was altered in the LVH rats, representing a reduction in the number of step-to-step junctions, which was consistent with previous research (29). Changes in Cx43 within the hypertrophic ventricles were rather complicated, including the synthesis, metabolism, redistribution, and mRNA expression of Cx43 (30). Research has demonstrated that Ang-II, endothelin-I, and transforming growth factor- $\beta$ stimulate the expression of Cx43 (31). Our findings indicate that endogenous $\mathrm{H}_{2} \mathrm{~S}$ may play an important role in regulating heart function and arrhythmia.

In this study we investigated the chronic effects of exogenous $\mathrm{H}_{2} \mathrm{~S}$ and proposed novel protective effects of $\mathrm{H}_{2} \mathrm{~S}$ on cardiac hypertrophy and fibrosis. The limitation is that we only observed the ameliorating- effects of $\mathrm{H}_{2} \mathrm{~S}$ on cardiac hypertrophy and fibrosis, but did not investigated the direct regulating effects of $\mathrm{H}_{2} \mathrm{~S}$ on ACE activity and mRNA expression. Neither did we observe the oxidative stress changes in myocytes, which will be the future research direction of our team.

In summary, our results demonstrated that $\mathrm{H}_{2} \mathrm{~S}$ has some beneficial effects on deferring or suppressing the development of left ventricle hypertrophy and cardiac fibrosis induced by abdominal aorta coarctation in rats. The mechanisms may be at least partially related to $\mathrm{H}_{2} \mathrm{~S}$, regarding its modulation of intracardiac renin-angiotensin system activity and $\mathrm{Cx} 43$.

\section{Acknowledgements}

This study was supported by the Foundation for Natural Science of Guangdong Province, China (no. 6033503).

\section{References}

1. Indolfi C, Di Lorenzo E, Perrino C, et al: Hydroxymethylglutaryl coenzyme A reductase inhibitor simvastatin prevents cardiac hypertrophy induced by pressure overload and inhibits p21ras activation. Circulation 106: 2118-2124, 2002.

2. Yasunari K, Maeda K, Nakamura M, et al: Left ventricular hypertrophy and angiotensin II receptor blocking agents. Curr Med Chem Cardiovasc Hematol Agents 3: 61-67, 2005.

3. Nishikimi T and Matsuoka H: Cardiac adrenomedullin: its role in cardiac hypertrophy and heart failure. Curr Med Chem Cardiovasc Hematol Agents 3: 231-242, 2005.

4. Manabe I, Shindo T, Nagai R, et al: Gene expression in fibroblasts and fibrosis: involvement in cardiac hypertrophy. Circ Res 91: 1103-1113, 2002

5. Brilla CG, Funck RC, Rupp H, et al: Lisinopril-mediated regression of myocardial fibrosis in patients with hypertensive heart disease. Circulation 102: 1388-1393, 2000. 
6. López B, Querejeta R, Varo N, et al: Usefulness of serum carboxy-terminal propeptide of procollagen type I in assessment of the cardioreparative ability of antihypertensive treatment in hypertensive patients. Circulation 104: 286-291, 2001.

7. Teunissen BE, Jongsma HJ and Bierhuizen MF: Regulation of myocardial connexins during hypertrophic remodeling. Eur Heart J 25: 1979-1989, 2004

8. Kostin S, Dammer S, Hein S, et al: Connexin43 expression and distribution in compensated and decompensated cardiac hypertrophy in patients with aortic stenosis. Cardiovasc Res 62 : 426-436, 2004.

9. Danik SB, Liu F and Zhang J: Modulation of cardiac gap junction expression and arrhythmic susceptibility. Circ Res 95: 1035-1041, 2004.

10. Moore PK, Bhatia M, Moochhala S, et al: Hydrogen sulfide: from the smell of the past to the mediator of the future? Trends Pharmacol Sci 24: 609-611, 2003.

11. Tang CS, Li XH, Du JB, et al: Hydrogen sulfide as a new endogenous gaseous transmitter in the cardiovascular system. Curr Vasc Pharmacol 4: 17-22, 2006.

12. Shibuya N, Tanaka M, Yoshida M, et al: 3-Mercaptopyruvate sulfurtransferase produces hydrogen sulfide and bound sulfane sulfur in the brain. Antioxid Redox Signal 11: 703-714, 2009

13. Shibuya N, Mikami Y, Kimura Y, et al: Vascular endothelium expresses 3-mercaptopyruvate sulfurtransferase and produces hydrogen sulfide. J Biochem 146: 623-626, 2009.

14. Elrod JW, Calvert JW and Morrison J: Hydrogen sulfide attenuates myocardial ischemia-reperfusion injury by preservation of mitochondrial function. Proc Natl Acad Sci USA 104: 15560-15565, 2007.

15. Zhao W, Zhang J, Lu Y, et al: The vasorelaxant effect of $\mathrm{H}_{2} \mathrm{~S}$ as a novel endogenous gaseous K (ATP) channel opener. EMBO J 20 : 6008-6016, 2001.

16. Bian JS, Yong QC, Pan TT, et al: Role of hydrogen sulfide in the cardioprotection caused by ischemic preconditioning in the rat heart and cardiac myocytes. J Pharmacol Exp Ther 316: 670-678, 2006.

17. Phrommintikul A, Tran L and Kompa A: Effects of a Rho kinase inhibitor on pressure overload induced cardiac hypertrophy and associated diastolic dysfunction. Am J Physiol Heart Circ Physiol 294: H1804-H1814, 2008.

18. Reddy K and Enwemeka CS: A simplified method for the analysis of hydroxyproline in biological tissues. Clin Biochem 29: 225-229, 1996
19. Izumiya Y, Kim S, Izumi Y, et al: Apoptosis signal-regulating kinase 1 plays a pivotal role in angiotensin II-induced cardiac hypertrophy and remodeling. Circ Res 93: 874-883, 2003.

20. Dahlöf B: Left ventricular hypertrophy and angiotensin II antagonists. Am J Hypertens 14: 174-182, 2001.

21. González A, López B, Díez J, et al: Fibrosis in hypertensive heart disease: role of the renin-angiotensin-aldosterone system. Med Clin North Am 88: 83-97, 2004.

22. Park CM, Nagel RL, Blumberg WE, et al: Sulfhemoglobin. Properties of partially sulfurated tetramers. J Biol Chem 261: 8805-8810, 1986.

23. Laggner $\mathrm{H}$, Hermann $\mathrm{M}$, Esterbauer $\mathrm{H}$, et al: The novel gaseous vasorelaxant hydrogen sulfide inhibits angiotensin-converting enzyme activity of endothelial cells. J. Hypertens 25: 2100-2104, 2007.

24. Kimura Y, Goto Y, Kimura H, et al: Hydrogen sulfide increases glutathione production and suppresses oxidative stress in mitochondria. Antioxid Redox Signal 12: 1-13, 2010.

25. Seddon M, Looi YH, Shah AM, et al: Oxidative stress and redox signalling in cardiac hypertrophy and heart failure. Heart 93 : 903-907, 2007.

26. Pahor M, Bernabei R, Sgadari A, et al: Enalapril prevents cardiac fibrosis and arrhythmias in hypertensive rats. Hypertension 18 148-157, 1991.

27. Li X, Jin H, Bin G, et al: Endogenous hydrogen sulfide regulates pulmonary artery collagen remodeling in rats with high pulmonary blood flow. Exp Biol Med (Maywood) 234: 504-512, 2009.

28. Roell W, Lewalter T, Sasse P, et al: Engraftment of connexin 43 -expressing cells prevents post-infarct arrhythmia. Nature 450: 819-824, 2007

29. Bacharova L, Plandorova J, Klimas J, et al: Discrepancy between increased left ventricular mass and 'normal' QRS voltage is associated with decreased connexin 43 expression in early stage of left ventricular hypertrophy in spontaneously hypertensive rats. J Electrocardiol 41: 730-734, 2008.

30. Severs NJ: Gap junction-mediated intercellular signaling in health and disease. Novartis Foundation Symposium 219: 188-211, 1999.

31. van Wamel AJ, Ruwhof C, van der Valk-Kokshoom LE, et al: The role of angiotensin II, endothelin-I and transforming growth factor-beta as autocrine/paracrine mediators of stretch-induced cardiomyocyte hypertrophy. Mol Cell Biochem 218: 113-124, 2001. 